\title{
Patients' Recall of Interaction with a Pharmacist During Hospital Admission
}

\author{
Douglas Doucette, Carole Goodine, Jodi Symes, and Erin Clarke
}

\begin{abstract}
Background: CSHP 2015 objective 1.5 proposes that at least 50\% of recently hospitalized patients or their caregivers will recall speaking with a pharmacist while in the hospital.
\end{abstract}

Objective: To determine the baseline prevalence of patients' recall of interaction with a pharmacist during their hospital admission and their level of satisfaction with these encounters, following a major reorganization of health authorities in New Brunswick.

Methods: Former inpatients from 27 units in 9 hospitals in the Horizon Health Network were randomly selected to complete a telephone survey within 5 to 7 months after discharge from hospital. Patients' responses were validated against pharmacists' documentation in the patients' health records.

Results: From June 2010 to July 2011, a total of 1028 former inpatients were screened, of whom 399 completed the telephone survey. More than half of the respondents were women (225 [56.4\%]), and the mean age was 67 years. Overall, 184 patients $(46.1 \%)$ recalled speaking with a pharmacist during their recent admission. Of these, 164 (89.1\%) were "satisfied" or "very satisfied" with these interactions. In addition, 332 respondents $(83.2 \%)$ indicated that if the hospital offered the opportunity to talk with a pharmacist who could help answer their questions about medications, they would take advantage of this service. The electronic hospital records of 181 patients (from 15 units at 3 sites) were analyzed to seek evidence of pharmacists' interventions or encounters (e.g., medication history, consultation). Pharmacist documentation was found in the health records of $166(91.7 \%)$ of all patients in this sample.

Conclusions: Almost half of former inpatients recalled speaking with a pharmacist during a recent hospital admission. The majority of patients were satisfied with these interactions and would welcome future services from hospital pharmacists.

Key words: clinical pharmacy services, patient expectations, patient satisfaction

Can J Hosp Pharm 2013;66(3):171-6

\section{RÉSUMÉ}

Contexte : L'objectif 1.5 visé du projet SCPH 2015 est qu’au moins $50 \%$ des patients hospitalisés récemment ou leurs aidants naturels se souviendront d'avoir rencontré un pharmacien au cours de leur épisode de soins.

Objectif: Déterminer la proportion initiale de patients qui se souviennent avoir interagi avec un pharmacien durant leur séjour à l'hôpital et leur degré de satisfaction par rapport à ces rencontres, par suite d'une importante réorganisation des régies de la santé du Nouveau-Brunswick.

Méthodes : Des patients qui avaient été admis dans 27 unités de 9 hôpitaux du Réseau de santé Horizon qui avaient été hospitalisés ont été choisis au hasard pour répondre à un sondage téléphonique dans les 5 à 7 mois suivant leur congé de l'hôpital. Les réponses des patients ont été validées en les comparant aux notes des pharmaciens dans les dossiers des patients.

Résultats : Du mois de juin 2010 au mois de juillet 2011, un nombre total de 1028 patients ayant été hospitalisés ont été présélectionnés et 399 d'entre eux ont répondu au sondage téléphonique. Plus de la moitié des répondants étaient des femmes $(225[56,4 \%])$ et l'âge moyen des répondants était de 67 ans. Dans l'ensemble, 184 patients (46,1\%) se souvenaient avoir parlé à un pharmacien durant leur récente hospitalisation. De ceux-ci, $164(89,1 \%)$ se sont dits " satisfaits " ou " très satisfaits " de leur rencontre. De plus, 153 (83,2\%) des répondants ont indiqué que si l'hôpital leur donnait l'occasion de parler à un pharmacien qui pourrait les aider à trouver des réponses à leurs questions sur les médicaments, ils profiteraient de ce service. Les dossiers informatisés de 181 patients (de 15 unités dans 3 sites) ont été analysés à la recherche de notes concernant les interventions des pharmaciens ou les rencontres avec ceux-ci (p. ex., historique des médicaments, consultation). Des notes de pharmaciens ont été trouvées dans les dossiers médicaux de 166 (91,7 \%) de l'ensemble des patients de cet échantillon.

Conclusions : Près de la moitié des patients se sont souvenus avoir parlé à un pharmacien durant leur récente hospitalisation. La majorité d'entre eux se sont dits satisfaits de ces interactions et seraient ouverts à se prévaloir des services de pharmaciens d'hôpitaux à l'avenir.

Mots clés : services de pharmacie clinique, attentes des patients, satisfaction des patients

[Traduction par l'éditeur] 


\section{INTRODUCTION}

$\mathrm{E}^{\mathrm{n}}$ nsuring quality of care in hospitals and health care systems is essential, given the often complex nature of interactions between patients and their illnesses, the variety of diagnostic and therapeutic measures available, and the demands of limited health care resources in Canada. National, provincial, and regional health authorities periodically report on wait times and patient satisfaction as indicators of health care quality. However, for pharmacy services delivered within a hospital setting, scant published data are available on the quality of care provided to patients.

The Canadian Society of Hospital Pharmacists (CSHP) has taken a national leadership role in promoting CSHP 2015, a practice excellence initiative for pharmacists in hospitals and related health care settings. ${ }^{1}$ The CSHP 2015 initiative is based on the ASHP 2015 program of the American Society of Health-System Pharmacists, adapted for the Canadian health care environment through extensive input from a wide range of hospital pharmacy stakeholders across Canada. CSHP 2015 is a patient-centred initiative with 6 major goals and 36 objectives to support effective, scientific, evidence-based, and safe medication use for patients through the positive contributions of hospital pharmacy teams. This national program applies to all patients, pharmacists, and institutional practice settings. ${ }^{2}$

One of the CSHP 2015 objectives aims to increase the prevalence of interactions between hospital pharmacists and their patients. More specifically, objective 1.5 states that "Pharmacists interface with inpatients or their caregivers in a meaningful way such that patients/caregivers will remember speaking with a pharmacist while in the hospital", with a target of $50 \% .{ }^{2,3}$ Working in partnership with the Editorial Board of the Hospital Pharmacy in Canada Survey (through its 2007/2008 national survey), CSHP collected data from 166 Canadian hospital pharmacies representing over 69000 beds. With regard to CSHP 2015 objective 1.5, the survey found that $11 \%$ of responding hospital pharmacies had achieved the target of $50 \%$ of hospitalized patients or their caregivers being able to recall speaking with a pharmacist while in hospital. ${ }^{4}$ A recent phone survey of patients discharged from hospital in a western Canadian health region found that $20.9 \%$ of respondents recalled speaking to a pharmacist. ${ }^{5}$

In 2008, New Brunswick's Minister of Health issued a directive that the 8 existing health authorities be reorganized into 2 regional health authorities. Horizon Health Network is the larger of the 2 new health authorities and is also the largest health authority in the Atlantic provinces, employing approximately 13000 staff and 1000 physicians in more than 100 facilities, clinics, and offices. Horizon Health Network has approximately 1600 hospital beds across 12 hospitals located in both rural and urban areas of New Brunswick. As of late 2012 the region employed 104 pharmacist full-time equivalents, the majority assigned to provide care to inpatients and outpatients in patient care wards, clinics, and emergency departments. Given that regionalization occurred only recently, Regional Pharmacy Services is currently in transition, examining the status of its operations and clinical services across all sites. The assignment of pharmacists to areas caring for patients with complex and high-risk medication needs has not yet been fully determined. Although the national baseline for CSHP 2015 objective 1.5 was recently established as $11 \%,{ }^{4}$ those data do not reflect the new organizational structure of Regional Pharmacy Services within the larger health authority. Pharmacy leadership wished to establish the new region's baseline status for this quality indicator and then to use this indicator to track progress in delivering a more patient-oriented pharmacy service in the future.

The aims of the study reported here were to determine the prevalence of patients' recall of interactions with a pharmacist during their hospital admission and to determine their level of satisfaction with these encounters. A telephone questionnaire was used to interview patients after discharge from hospital. Survey responses were validated by searching for pharmacists' documentation in patients' electronic health records (EHRs).

\section{METHODS}

\section{Design and Setting}

A standardized telephone survey was administered to patients from selected patient care units in 9 hospitals within Horizon Health Network, New Brunswick. Eligible participants were acute care patients who had been discharged from any of the 9 hospitals 5 to 7 months before the survey. Patients were excluded if any of the following criteria applied: age less than 18 years; length of stay less than $24 \mathrm{~h}$; death, discharge to a nursing or special care facility, or transfer to another acute care unit or facility; presence of a medical condition limiting the person's ability to recall or provide information (e.g., dementia, result on Mini Mental State Examination less than 23/30, clock score less than 9, verbal or hearing impairment). The Research Ethics Board of Horizon Health Network approved the project as a minimal risk study.

Patient care units in the participating facilities were selected in consultation with local pharmacy managers. Most of the selected units had a pharmacist assigned to direct patient care duties. The Health Records department provided lists of discharged patients from the selected units of each facility for the specified study period. Patients selected at random from these lists were contacted by telephone to request verbal consent to participate in a standardized survey (see Appendix 1 , available online at www.cjhp-online.ca/index.php/cjhp/issue/ view/93/showToc, for the script used to seek consent). A 
maximum of 2 attempts to contact each former patient were made before the person was designated as "unable to be contacted". For those who consented to participate, interviewers (pharmacy students) administered the nonvalidated survey in English or French, according to the participant's preference, using a prepared script (see Appendix 2, available online at www.cjhp-online.ca/index.php/cjhp/issue/view/93/showToc) and recorded the person's responses.

\section{Data Collection}

Data collection was initiated for patients discharged during March 2010. An error related to the length-of-stay parameter in the Health Records report resulted in a far lower than expected yield of potential participants. Nonetheless, eligible patients were screened, and 38 surveys were completed from June to August 2010. The report criteria were reviewed, and the error was corrected late in 2010. The Research Ethics Board granted a request to retrieve another list of discharged patients (discharge dates in November and December 2010) from Health Records. Following the same protocol, potential participants from the second list were screened and contacted by pharmacy students between May and July 2011 to reach the recruitment target (as described below).

The following demographic data were retrieved from EHRs in each facility: name, sex, age, personal health care number (provincial Medicare number), treatment unit, and discharge hospital. During the telephone interviews, based on the scripted survey, participants were asked if they recalled speaking with a pharmacist during their admission, their overall level of satisfaction with such interactions (if they occurred), and their interest in increased access to pharmacist services in future hospital admissions. EHRs were searched for evidence of pharmacists' documentation of interventions or encounters with the patients (e.g., progress note, consultation, assessment). Because access to electronic documentation tools was not uniformly available in the health region, it was decided to analyze documentation data only for those sites where use of electronic tools was common pharmacy practice, to avoid undue time and effort to retrieve paper charts.

The pharmacy student interviewers $(n=11)$ estimated that a typical interview took 5 to 10 min to complete (including the time to read and obtain verbal consent), plus another $5 \mathrm{~min}$ to search the EHR for evidence of pharmacist documentation (for sites where such records were available). The co-investigators at individual sites (C.G., J.S., E.C.) submitted data for each site to the principal investigator (D.D.), who reviewed the data before entry into the study's master database by a student researcher.

\section{Sample Size}

Using a Bayesian method, it was estimated that 384 survey respondents were needed to detect an estimated prevalence of 50\% with $95 \%$ confidence. ${ }^{6}$ According to recent discharge lists provided by the Health Records department, a total of 1530 patients were discharged monthly, on average, from the 27 patient care units participating in the study.

\section{Data Analysis}

The primary outcome was the proportion of patients who recalled an interaction with a pharmacist on the patient care unit where they were treated. Subanalyses were conducted to compare responses by sex, age group (18-30, 31-45, 46-55, 56-65, 66-75, and 76-99 years), and hospital type (regional versus community). Secondary outcomes were the patients' satisfaction with their interactions with a pharmacist (on a 5-point Likert scale, where 1 was "very dissatisfied" and 5 was "very satisfied"); correlation between a patient's recall of an interaction and any pharmacist-recorded interventions (based on pharmacists' documentation in the EHR), to assess the reliability of data collected from patients; and the percentage of participants who expressed a desire to talk with a pharmacist to get answers to questions about their medications. ${ }^{7}$ Participants were also asked to identify the service or information that they would like to receive from pharmacists during a hospital admission to assist them in managing their medications. These responses were captured in an open narrative format and were subjected to content analysis, the results of which are reported elsewhere. ${ }^{8}$

The Horizon Health Research Office performed data analysis using STATISTICA 6.0 (StatSoft) and SPSS version 20.0 (IBM) software. Descriptive statistics were used for demographic data. The primary outcome was analyzed with the $\chi^{2}$ test. Kruskal-Wallis analysis of variance was used to detect subgroup differences in participants' satisfaction. The Spearman correlation coefficient was used for analysis of patients' recall and pharmacists' documentation.

\section{RESULTS}

Of 2004 former inpatients discharged from 27 units during the 3 months for which patient lists were prepared, 1028 were screened and 399 completed the phone survey. Of those excluded from the survey, 374 could not be contacted by phone, 183 were determined to have criteria for exclusion (e.g., death, transfer to another facility, cognitive impairment), and 72 declined to participate. The mean age of survey respondents was 67 years (range 19 to 94 years), and 225 (56.4\%) were women.

In terms of the primary outcome, 184 (46.1\%) of the 399 respondents recalled speaking with a pharmacist during their 
hospital admission, whereas 155 (38.8\%) did not recall, 59 (14.8\%) stated, "Don't know", and $1(0.3 \%)$ declined to answer. The proportion of patients recalling an interaction with a pharmacist $(0.461,95 \%$ confidence interval 0.411-0.509) was not significantly different from the CSHP 2015 target of $50 \%(p=0.11, \mathrm{Z}$-score $=1.6)$. However, significant differences in patient recall were observed among the 4 main geographic areas in the region $(20 \%$ to $64 \% ; p<0.001$; Figure 1$)$. The proportion of patients who recalled an interaction with a pharmacist was significantly greater than expected in zone 1 and less than expected in zones 3 and 7.

Among participants 76-99 years of age, a significantly greater proportion did not recall speaking to a pharmacist, relative to the other age groups $(p=0.011)$ (Figure 2). The proportion of patients who recalled interaction with a pharmacist was not significantly different among those discharged from regional hospitals versus those discharged from community hospitals ( $48.1 \%$ versus $38.8 \%, p=0.13$; Figure $3)$. There was no difference in recall between men and women ( $p=0.35$; data not shown).

Of the 184 patients who recalled interaction with a pharmacist, $89.1 \%$ rated their satisfaction with the interaction as "satisfied" $(n=26)$ or "very satisfied" $(n=138)$. There was no significant difference in satisfaction scores according to sex, zone, or age group. Participants were also asked, "If the hospital offered you the opportunity to talk with a pharmacist who could help answer your questions about medications, would you want to talk to the pharmacist?" This offer of service yielded a positive response from 332 (83.2\%) of the participants, whereas $45(11.3 \%)$ answered "no", and 22 (5.5\%) "did not know".

For the comparison of patients' recall with documented pharmacy interventions, the analysis was limited to 184 patients from the 15 patient care units where pharmacists' clinical documentation was expected to be in EHRs rather than paper charts. Of these 184 patients, 3 with missing data were excluded, and the EHRs of the remaining 181 patients were examined for the presence of pharmacy documentation. Fiftynine $(32.6 \%)$ of these 181 patients recalled an interaction with a pharmacist during their admission and a corresponding pharmacist intervention was recorded in the EHR; 35 patients (19.3\%) did not recall an interaction and had no pharmacist note in the EHR, 25 (13.8\%) did not recall an interaction but electronic documentation indicated that a pharmacist had seen the patient, and 62 patients $(34.3 \%)$ recalled an interaction but no intervention was recorded in the EHR.

The study team was concerned that pharmacists' electronic notes were found in only $46.4 \%$ of patients' charts (i.e., [59 + 25]/181), which might be viewed as "non-compliance" with requirements for clinical documentation. It was noted that many patients interact with pharmacy team members at the

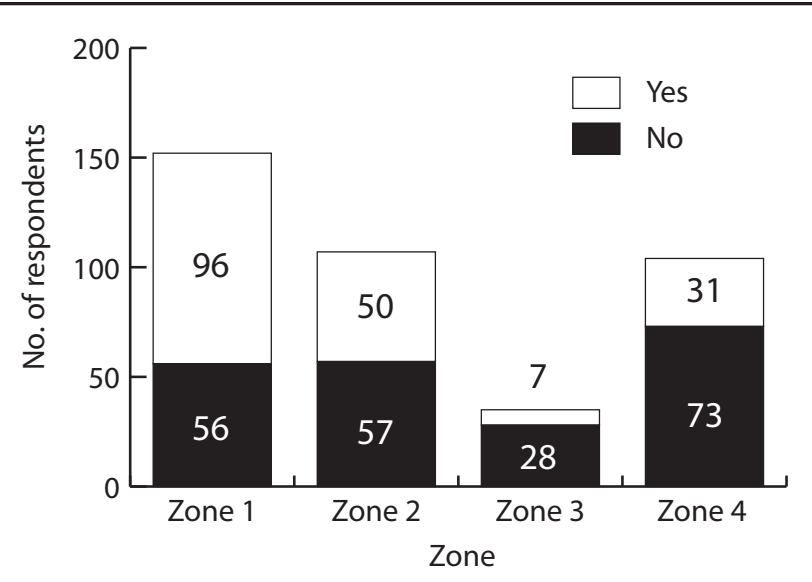

Figure 1. Patients' recall of interaction with a pharmacist by zone. The "No" category in this graph also includes "don't know" responses. One patient declined to answer this question and was excluded from the analysis; therefore, the sample size was 398.

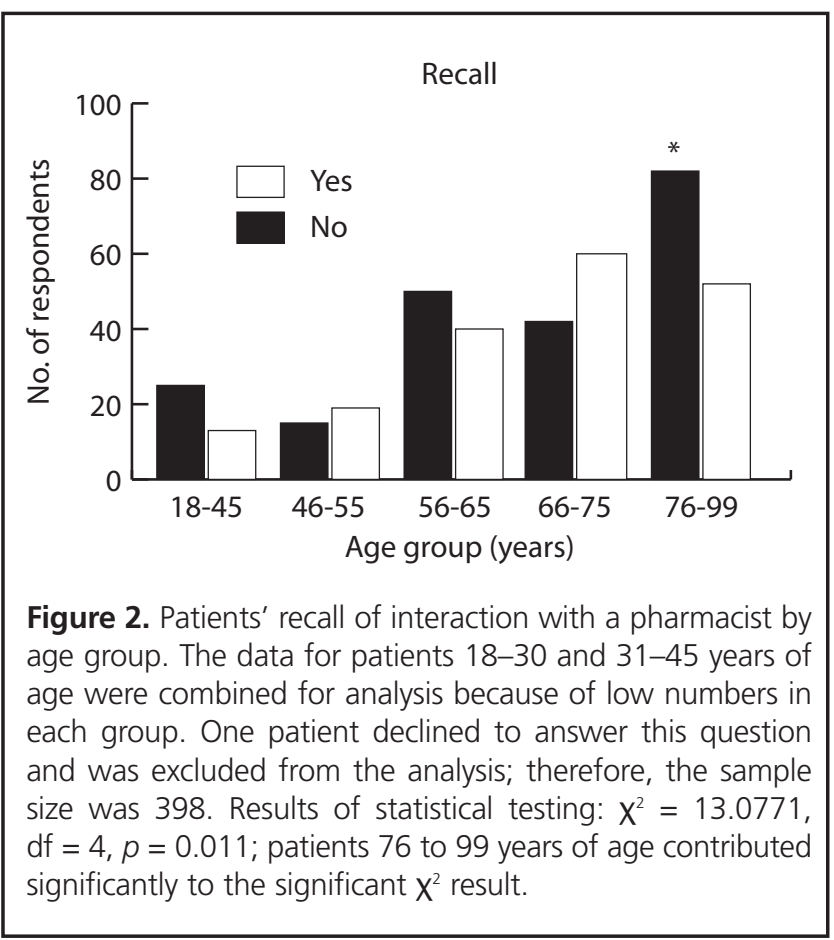

time of admission, for the provision of medication histories, a process that is captured by manual documentation practices at all sites. As such, relying solely on electronic documentation may not reflect current practice, even at those sites where EHRs are available, because of hybrid electronic and manual charting systems.

Therefore, a post hoc analysis was conducted by reviewing manual charts for the patients with no pharmacist intervention documented in the EHR $(35+62=97$ patients from the 


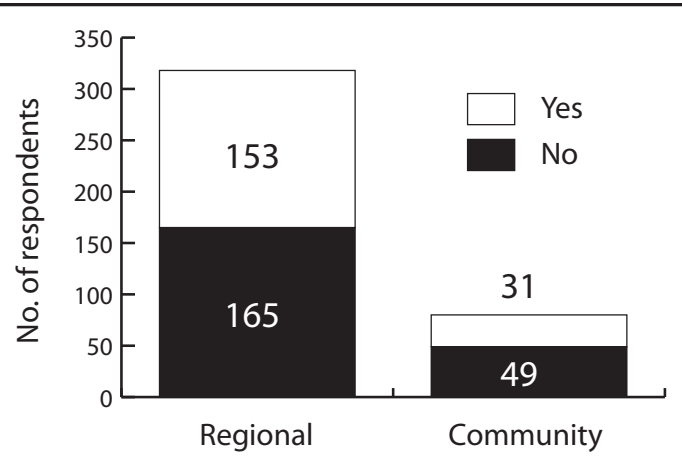

Figure 3. Patients' recall of interaction with a pharmacist by type of hospital (regional versus community). The "No" category in this graph also includes "don't know" responses. One patient declined to answer this question and was excluded from the analysis; therefore, the sample size was 398

previously described analysis). The Health Records department was able to provide charts for 85 of these 97 patients, and manual chart documentation by a pharmacist (in the form of a medication history or medication reconciliation) was found in 82 of these 85 charts. With the inclusion of these post hoc results, it was determined that pharmacists' manual or electronic chart notes were found in $166(91.7 \%)$ of 181 patient records sampled (Table 1).

\section{DISCUSSION}

This telephone survey showed that $46.1 \%$ of former inpatients recalled an interaction with a hospital pharmacist within 5 to 7 months after their discharge from selected units in Horizon Health hospitals. These findings were statistically consistent with the CSHP 2015 target of $50 \%^{1-4}$ and were more than double the result from a similar study conducted in patients 2 months after discharge from Calgary hospitals. ${ }^{5}$ Statistically significant differences were noted among the 4 zones in this health authority but not between regional and community hospitals. The differences by both geographic area and hospital type were thought to be related to differences in pharmacist staffing levels on the units sampled (pharmacist assigned to a ward on a regular versus responsive basis) and the stage of development of clinical pharmacy programs within participating hospitals.

Of respondents who recalled meeting a pharmacist during their hospital stay, a total of $89.1 \%$ were either satisfied or very satisfied with that interaction. This finding was consistent regardless of sex, age, or hospital where the care had been provided. The majority of study participants $(83.2 \%)$ expressed willingness to accept an offer of clinical pharmacy services at a future hospital admission. Narrative responses to a question
Table 1. Patients' Recall of Interaction with a Pharmacist in Relation to Documented Pharmacist Interventions*

\begin{tabular}{|c|c|c|c|}
\hline \multirow[b]{2}{*}{ Pharmacy Note } & \multicolumn{2}{|c|}{$\begin{array}{l}\text { No. (\%) of Patients } \\
\text { Recalling Interactiont }\end{array}$} & \multirow[b]{2}{*}{ Total } \\
\hline & Yes & No & \\
\hline Present & $117(64.6)$ & $49(27.1)$ & $166(91.7)$ \\
\hline Absent & $4 \quad(2.2)$ & 11 (6.1) & 15 (8.3) \\
\hline Total & $121(66.9)$ & $60(33.1)$ & $181(100)$ \\
\hline
\end{tabular}

*Documentation in either electronic or paper patient records. †All percentages are based on the total sample of 181 patients.

about what services or information patients would like to receive from hospital pharmacists were subjected to content analysis, which is reported separately. ${ }^{8}$

The results of this study will help to determine where gaps may exist in the Horizon Health Regional Pharmacy Services specifically related to patients' interactions with hospital pharmacists. As Horizon Health continues to implement the CSHP 2015 project, these findings will assist the management team in developing quality initiatives to improve the level of direct patient care services provided by pharmacists in the region's facilities. These results will also assist in efforts to increase the visibility of Pharmacy Services to patients and their families and to increase their awareness of the pharmacist's role as a valued member of the health care team.

This study had several strengths, including use of a standard questionnaire, generation of widely applicable results, and support of the CSHP 2015 initiative. The questionnaire used questions about recall and satisfaction that were administered in a previously published study, ${ }^{5}$ and participants were able to complete the survey in English or French. The participating patients had been discharged from a variety of general and specialized units with and without routine pharmacist presence and from large regional teaching and smaller community hospitals, which made the results widely applicable within this health authority and perhaps to other health authorities of similar demographic characteristics and/or levels of clinical pharmacy service. The primary outcome of $46.1 \%$ of patients recalling an interaction with a hospital pharmacist demonstrates that $50 \%$ is a reasonable and achievable target under the CSHP 2015 initiative.

The limitations of this study included possible recall and sampling bias and the length of the intervals between pharmacist contact (if it occurred) and hospital discharge and between discharge and administration of the phone survey. Patient recall is susceptible to bias. For example, a person might have given a positive response when asked about interactions simply because the question was asked. Attempts were made to minimize this effect by excluding patients with memory or other sensory deficits and by correlating patients' recall and chart documen- 
tation. Older persons often have more difficulty recalling information than younger persons. ${ }^{9}$ In this study, the oldest age group (76-99 years) had a significantly greater proportion of participants who did not recall speaking to a pharmacist relative to the other age groups. Although patients who recalled meeting a pharmacist were asked about their level of satisfaction, the nature of their encounters was not explored. Recognizing that a given patient may encounter a multitude of caregivers who discuss medication during even a brief admission, it was difficult to determine whether patients who recalled interaction with a pharmacist had actually been visited by or had actually talked with a pharmacist. Attempts were made to verify whether a pharmacist had in fact provided services to patients who recalled such interactions, by checking for the presence of clinical documentation in patients' health records. Although the original intention was to administer questionnaires to patients within 2 to 3 months after discharge, the length of time to obtain lists of potential participants depended on Health Records staff completing coding activities for all participating sites. Despite being unable to contact patients until 5 to 7 months after their admission, the results indicated that many patients did recall these interactions during their hospital admission. Former inpatients were recruited mainly from units where pharmacists were assigned, but some came from units where pharmacists were not routinely present. Sampling patients discharged from a wider spectrum of inpatient units may lead to lower rate of recall for interactions with a pharmacist. Despite these limitations, it is still felt that the study results are valid and will benefit the health authority, Regional Pharmacy Services, and Horizon Health patients as means of improving the services provided by the region's pharmacy teams are explored.

\section{CONCLUSIONS}

Overall, $46.1 \%$ of former inpatients recalled speaking with a pharmacist during their hospital stay. The majority of those who recalled an interaction were satisfied with it and would welcome future services from hospital pharmacists. A content analysis of patient expectations for hospital pharmacy clinical services is reported separately. ${ }^{8}$

\section{References}

1. CSHP 2015: targeting excellence in pharmacy practice. Ottawa (ON): Canadian Society of Hospital Pharmacists; 2013 [cited 2013 May 1]. Available from: www.cshp.ca/programs/cshp2015/index_e.asp

2. CSHP 2015 crosswalk. Goals and objectives for pharmacy practice in hospitals \& related healthcare settings to be achieved by 2015. Ottawa (ON): Canadian Society of Hospital Pharmacists; 2009 Dec [cited 2013 May 13]. Available from: http://cshp.ca/dms/dmsView/1_Crosswalk2011-Revision-FINAL-\%282\%29---Nov-2011.pdf
3. CSHP 2015 survey of facilities, October to December 2009. CSHP 2015 goals and objectives for pharmacy practice in hospitals \& related healthcare settings to be achieved by 2015. Ottawa (ON): Canadian Society of Hospital Pharmacists; 2009 [cited 2013 May 1]. Available from: www.cshp.ca/dms/dmsView/1_CSHP-2015-Survey-of-Facilities_Feb.pdf

4. Musing E. Chapter J: CSHP 2015. In: Babich M, Bussières JF, Hall KW, Harding J, Johnson N, Lefebvre P, et al., editors. Hospital pharmacy in Canada 2007/2008 report. p. 81-9. Available from: www.lillyhospitalsurvey.ca/ hpc2/content/2008_report/cshp_2015.pdf

5. Romonko Slack L, Ing L. Prevalence and satisfaction of discharged patients who recall interacting with a pharmacist during a hospital stay. Can J Hosp Pharm. 2009;62(3):204-8.

6. Lwanga SK, Lemeshow S. Sample size determination in health studies: a practical manual. Geneva (Switzerland): World Health Organization; 1991.

7. Top patient concerns 2002: omnibus survey results. Bethesda (MD): American Society of Health System Pharmacists; 2002 [cited 2013 May 1]. Available from: www.ashp.org/s_ashp/docs/files/PR_ResearchReport.pdf

8. Gould O, Buckley P, Doucette D. What patients want: preferences regarding hospital pharmacy services. Can J Hosp Pharm. 2013;66(3):177-83.

9. Gould ON, Wasylkiw L, Rogers EE, MacPherson M. Pharmacist or physician: age differences in satisfaction with medical advice. Can J Aging. 2006;25(2):207-17.

Douglas Doucette, RPh, BSc(Pharm), PharmD, FCSHP, is Regional Pharmacy Clinical Manager, Pharmacy Services, Horizon Health Network, New Brunswick, and Associate Professor, College of Pharmacy, Dalhousie University, Halifax, Nova Scotia.

Carole Goodine, BSc(Pharm), PharmD, is Pharmacy Clinical Manager, Dr Everett Chalmers Regional Hospital, Fredericton, New Brunswick.

Jodi Symes, BSc(Pharm), PharmD, is Pharmacy Clinical Manager, Saint John Regional Hospital, Saint John, New Brunswick.

Erin Clarke, BSc(Pharm), is a Pharmacist, The Moncton Hospital, Moncton, New Brunswick.

Competing interests: Douglas Doucette has received payment from Eli Lilly for board membership with the Hospital Pharmacy in Canada Report, speaker's fees from AstraZeneca, and payment from Rogers Publishing for manuscript preparation for the journal Pharmacy Practice. None declared for other authors.

\section{Address correspondence to:}

Dr Douglas Doucette

Pharmacy Services, Horizon Health Network

135 MacBeath Avenue

Moncton NB E1C $6 Z 8$

e-mail: Douglas.Doucette@HorizonNB.ca

\section{Acknowledgements}

This study was supported by a grant to Horizon Health Network from Medbuy.

We acknowledge Scott Simpson, BSc(Pharm), Miramichi Regional Hospital, for support of this study at his hospital site; the Horizon Health Network Office of Research Services, for support in data analysis; the summer students who conducted all of the phone interviews to gather data; and the patients who shared their views on the services provided during their admissions. 